\title{
A tale of two tails: asymmetry in Great Grey Shrike (Lanius excubitor)
}

\author{
Reuven Yosef ${ }^{1^{*}}$, Anna Maria Kubicka², Martin Brandsma ${ }^{3}$ and Piotr Tryjanowski ${ }^{2}$
}

\begin{abstract}
Background: Asymmetry in the wild is a controversial, and to date, unresolved subject. Fluctuating asymmetry (FA) is the developmental instability (intra-individual variation) while, directional asymmetry (DA) expresses the asymmetry of the population mean.

Methods: We analysed 63 Great Grey Shrike (Lanius excubitor) skins at the Naturalis Biodiversity Center, Leiden, the Netherlands. The black markings on the tails were digitized in order to evaluate the symmetry of the two sides of each shrike. Ptilochronology helped understand if nutritional condition affected symmetry.

Results: ANOVA revealed no significant differences in size of the tail between sexes ( $F=1.67, p>0.05)$. However, there was significant difference in the shape of the black area in feathers between the sexes $(F=2.14, p<0.05)$, and males had more elongated and slender black areas. Further, DA was observed only in males, but FA was noted in both sexes. Spearman correlation showed no significant association between FA score and tail features in both the sexes. However, in females, we observed a negative significant correlation between the number of fault and growth bars. The shape of the black area in the tail displayed no statistically significant association with the tail features in both sexes although growth bars influenced tail shape more than the number of fault bars.
\end{abstract}

Conclusions: We concluded that the characteristics discovered by us need to also be checked in the field and if they can be used to sex individuals. Also, chromatic manipulative studies are require to verify if DA influences sexual selection in the Great Grey Shrike.

Keywords: Lanius excubitor, Ptilochronology, Geometric morphometrics, Fluctuating, Directional asymmetry

\section{Background}

In wild animals, especially avian, the tail has been ascribed a wide range of functions and capabilities. These include roles in aerodynamics (e.g., Pennycuick 1975; Mayburg et al. 2001), inter- and intra-specific communication (cf. Ortolani 1999), and sexual selection (Darwin 1871; Hamilton and Zuk 1982; Møller 1994). Thomas (1993) concluded that much of the variation in the level of fluctuating asymmetry (FA) in the tail can be explained by natural selection for aerodynamic efficiency. Further, Balmford et al. (1993) summarized their study by saying that patterns of FA in long tails may often be better understood in a context of natural rather than sexual

\footnotetext{
*Correspondence: ryosef60@gmail.com

${ }^{1}$ Ben-Gurion University of the Negev - Eilat Campus, P.O. Box 272, 88106 Eilat, Israel

Full list of author information is available at the end of the article
}

selection, and that natural selection favored symmetrical wings and tails in birds. In addition to the morphology of the tail, the coloration and markings are also found to be important signals that can influence individual fitness (cf. Endler 2000).

The subject of asymmetry in the wild is a very controversial, and to date, unresolved subject (e.g., Markow and Clarke 1997; Palmer 1999, 2000). Fluctuating asymmetry is described as developmental instability (intraindividual variation) while directional asymmetry (DA) expresses the asymmetry of the population mean (e.g. Mitteroecker and Gunz 2009). Several reviews have tried to address the subject of how FA could be influenced by genetic and environmental factors, and its ultimate influence on the fitness of an individual or a population (e.g., Møller and Thornhill 1997; Vøllestad et al. 1999; Swaddle 2003). Many studies have succeeded in demonstrating 
the adaptive significance and influence of asymmetry on evolutionary paradigms, such as sexual selection (e.g., Møller and Höglund 1991; Andersson 1994; Møller et al. 1998; Gonzalez-Jaramillo and de La Cueva 2010).

Swaddle (2003) compiled some of the studies which demonstrated relationships between fitness and asymmetry and which decreased competitive (Sneddon and Swaddle 1999) and mating ability (Blackenhorn et al. 1998), or predation (Swaddle 1997). But asymmetry has also been shown to affect sexual selection (Swaddle and Cuthill 1994; Morris and Casey 1998; Shykoff and Møller 1999). Swaddle (2003) summarised that environmental factors, including stress, could determine the expressions of FA and suggested that it has little or no genetic origin. A non-invasive technique to determine relative stress in individuals is ptilochronology (e.g., Yosef and Grubb 1994).

Ptilochronology (Grubb 1989) is based on the evaluation of the width of feather growth bars during each 24-h period at the time of moult and depends on the amount of energy and nutrients invested by an individual into the regeneration process, which at the same time depends on the nutritional condition and quality of an individual (Grubb 1989, 2006). Growth bar width indicates an individual's relative nutritional condition. Other indices of nutritional condition, such as total body mass or fat percentages, are more commonly applied (Grubb 1989, 2006). Age and sex have also been proved to influence width of growth bars, and the total length and mass of both an induced feather and the original feather grown from the same follicle during the preceding pre-basic molt varied significantly with the age and sex of Northern Cardinals (Cardinalis cardinalis; Grubb et al. 1991). However, the interpretation of these traditional indices is often questioned. In certain circumstances, the highest body mass or fat percent does not correspond with the highest nutritional condition of an individual (Grubb 1995). Feather growth as an index of the nutritional condition is based on natural selection, which forces birds to regenerate lost feathers as rapidly as possible. Therefore, birds in better nutritional condition regenerate feathers much faster than individuals in poor condition (Grubb et al. 1991; Grubb 2006). Thus, feather quality is a relatively accurate indicator of an individual's quality.

Also, we took into account the fact that Prentice et al. (2008) found no relationship between the occurrence of fault bars and degree of bilateral asymmetry, and concluded that FA and fault bar occurrence should not be used interchangeably as bio-indicators. Hence, we ignored the data pertaining to fault bars on the feathers and only considered a combination of the study of the asymmetry of the tail feathers of Great Grey Shrike (Lanius excubitor) combined with ptilochronology to allow us to elucidate a possible relationship between these two states that are determined simultaneously during the growth of the feather. That is why, the first aim of the study was to analyse relationship between DA and FA of the black markings on both sides of the tail, and their related nutritional condition. We wished to understand whether the two parameters could be influenced by nutritional stress at the time of moult. Although the only paper on shrike that we found that studied the effects of the melanin-based tail patterns on individual quality was in Lesser Grey Shrikes (L. minor; Krištín et al. 2006), the relative number of skins in the museum available for analyses and the similarity between the two species convinced us to study the tail patterns of Great Grey Shrike (also see Hromada et al. 2003b). Also, the Great Grey Shrike is a relatively well-studied species of True Shrike (Laniidae spp., Dylewski et al. 2017). Aspects of sexual selection (Yosef and Pinshow 1989; Votypka et al. 2003), courtship (Tryjanowski and Hromada 2005), reproduction (Degen et al. 1992), parasites (Szczykutowicz et al. 2006), foraging niche (Hromada et al. 2003a), and a wide range of other subjects (e.g., Lorenz et al. 1968; Yosef and Pinshow 2005) have been studied in this species. Hence, our second aim was to try to assess if there are differences in tail patterns and coloration between the sexes. We hoped that if indeed we are able to find differences, this might help explain the function of these different markings.

\section{Methods}

The species is of special interest to Martin Brandsma (MB; www.martinbrandsma.nl), an artist who uses the species extensively as a focal subject for his exhibitions worldwide. One of his projects is to meticulously draw the black markings on the tails of Great Grey Shrikes in museum collections. Upon bringing this to our attention we devised a study wherein, in order to better understand asymmetry in the study species, we decided to apply in parallel a comparative technique which represents the nutritional condition of the bird in the form of growth bars known as ptilochronology (Grubb 1989).

MB and Reuven Yosef (RY) met at the Naturalis Biodiversity Center at Leiden, the Netherlands, in August 2014 and evaluated 324 skins of Great Grey Shrike. One of the main purpose was to analyse relationship between the tail shape and its features (growth and fault bars) using geometric morphometrics. This method is very strict in terms of the number of landmarks (each analyzed shape must contain the same number of landmarks) therefore, we could carry out analyses only on tails with all preserved feathers. That is the reason, due to varying states of preservation, and excluding those with missing feathers and pulli, only 198 (61.1\%) were considered to be in 
acceptable shape and were included in the study, but owing to other considerations the final analyses were done on 63 (19.4\%) tails.

The skins analysed were collected between the years 1844 and 1983 and were collected one (1.6\%) each from Canada, Czech Republic, Kyrgyzstan, Romania; two (3.2\%) each from Switzerland and Italy; three (4.8\%) each from China, France, and Russia; and 52 (82.5\%) were collected in the Netherlands.

RY first conducted the ptilochronology evaluation and then MB photographed the tails of the skins. In order to respect the protocols of a blind test, independently of each other, RY marked the growth bars on the feathers on index cards at the museum but measured the growth bars at home in Israel while MB traced the black markings on the complete tail of the Great Grey Shrike skins in his studio (Fig. 1). On each feather, 10 growth bars centred on the point two-thirds of the distance toward the tip of the feather were measured by RY, who served as a blind test (e.g., Grubb and Yosef 1994; Gombobaatar et al. 2009; Bujoczek et al. 2011).

As in all museum skins, the tails were closed, and required each rectrix to be transferred separately. All black areas on the tail feathers, including the shaft, were transferred with a sharp pencil in two steps: (a) with points (through the feather) and (b) connecting the points in contour lines. This transfer was done on a fixed standardized template of the rectrices (Additional file 1: Figure S1) because not all feathers are of the same size. The next step was to fill all parts within the contour lines in 'black fields' (with Photoshop CS 6). Under each image the collection number of the relevant skin was noted.

Of the 198 tails whose black markings were traced, we included in our final analyses only 63 Great Grey Shrike tails (19.4\%; 28 females and 35 males) where all 12 of the rectrix feathers were intact and the markings sharpest. We also verified that the skins included in our study were collected in regions that are today recognised as the geographic distribution of L. excubitor and not that of others

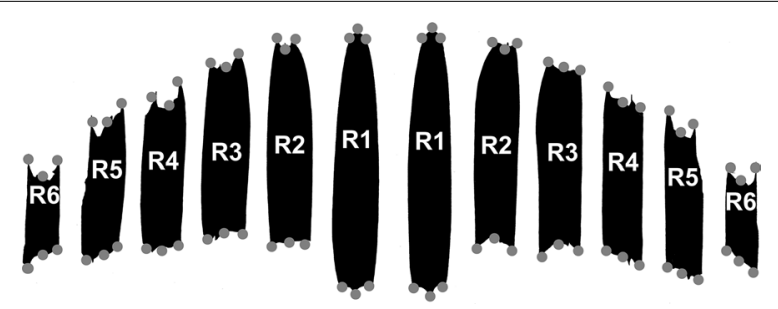

Fig. 1 Example of black areas marked on rectrices of the Great Grey Shrike (Lanius excubitor) with landmarks. Skin 29,692 from the Museum of Natural History, Leiden, the Netherlands that were later recognised as separate species (e.g., $L$. meridionalis; Hernandez et al. 2004; but see Olsson et al. 2010). For each tail, 72 landmarks were distributed on the black area of the feathers using tpsDig2 software (Fig. 1; Rohlf 2010). A maximum number of landmarks was established in order to reconstruct the tail markings as completely as possible. Six landmarks were digitised on each black area of the feather, three on the proximal and three on the distal end. One of the main purposes of our study was to analyse DA and FA of the black sections of the shrike's tail. Thus, the landmarks were digitised twice on each individual. Double distribution was also used to estimate measurement error in the landmarks' position.

\section{Statistical analysis}

Before statistical analysis, a Generalised Procrustes Analysis (GPA) was used for landmark superimposition, and centroid size was employed as the size measurement. Centroid size was calculated as the sum of the squared distances among all pairs of landmarks (e.g. Zeldith et al. 2004). In order to obtain the measurement error associated with landmark digitisation, Procrustes ANOVA test was carried out to analyse whether the variation between double distributions of landmarks on the same individual's tail was greater than that between samples. Since size effects can be an important component of shape variation in biological studies (Outomuro and Johansson 2017), the association between the tail shape and centroid size was analysed using regression analysis.

To analyse the significance of the differences in tail shape between sexes, the Procrustes ANOVA test was also carried out. We used principal components analysis (PCA) to describe major trends in shape variation within the sample. The PCA was conducted taking sex into account.

Based on Klingenberg (2011), in order to detect the existence of DA and FA in tails, the Procrustes ANOVA was conducted separately for females and males. Directional asymmetry is a measure of the mean difference between the original and mirrored copy of each individual. In turn, FA shows the dispersion of left-right differences within individuals. One of the main purposes of this study was to analyse whether a tail's features (growth and fault bars) are associated with FA scores. Hence, individual levels of FA were conducted in Mahalanobis distances using MorphoJ (Klingenberg 2011). We used the Mahalanobis distance to characterise the FA of each individual because this approach takes into account that some shape features are more variable than others (Klingenberg 2015). In order to find the association between FA score and the tail's features a Spearman correlation was conducted. Further, in order to analyse whether 
individual FA levels differ between sexes, the Mahalanobis distances were analysed using ANOVA test.

Two-block partial least-squares (PLS) were calculated to study the relationships between FA of the tail shape and sets of tail's features (growth and fault bars). This is a test which enables the calculation of covariation between two or more blocks of variables (Slice 2007; Mitteroecker and Gunz 2009). The purpose of the PLS is to link the two blocks using the fewest dimensions possible (for more details see McIntosh et al. 1996). Moreover, this test shows which variable, in our case the tail features, has the greatest influence on the shape of the shrike's tail. The statistical significance of the PLS analysis was run for each sex separately and tested using a permutation test of 10,000 randomisation rounds.

In all statistical analyses the $p$ value was significant at 0.05 . Geometric morphometric analyses were conducted using MorphoJ software (version 1.06d; Klingenberg 2011). After that statistical analyses of FA scores were conducted using SPSS software (version 23.0.0.0).

\section{Results}

The results showed that variation between samples $\left(\mathrm{MS}=9.8 \times 10^{-6}\right)$ was much larger than that between double distributions of landmarks for both observers $\left(\mathrm{MS}=1.9 \times 10^{-7}\right)$. Moreover, the ANOVA test showed no significant differences $(F=1.23, p=0.09)$ between repeated landmark distributions; hence, high intra- and interobserver agreement was confirmed.
The regression analysis showed a significant association between tail shape and size in females (percent of predicted $=27.97 \%, p<0.0001$ ) and males (percent of predicted $=26.79 \%, p<0.0001$ ), thus the rest of the statistical analysis was conducted taking into account the centroid size of the object. The Procrustes ANOVA test revealed no significant differences in size of the tail between sexes $(F=1.67, p>0.05)$ but a significant difference in the shape of the black area in feathers between females and males $(F=2.14, p<0.05)$. Feathers of males were characterised by more elongated and slender black areas on the feathers than that of females.

The PCA test was conducted with the centroid size of each individual taken into account. PC1 in both sexes explained $30.40 \%$ of the variation, in turn, $\mathrm{PC} 2$ in females and males was responsible for $14.62 \%$ of the variability (Fig. 2). The shrikes with positive values of PC1 are characterised by shorter black area in the tail than individuals with negative values of PC1. In turn, the positive values of PC2 are responsible for the slender black area in the shrike's tail. Individuals with negative values of PC2 have much wider and slightly elongated black area in the distal part of the tail.

The Procrustes ANOVA shape results showed that DA was observed only in males (Fig. 3), but FA was noted in both sexes of shrike (Table 1). However, there were no significant differences in Mahalanobis distance which show individual levels of FA between sexes $(F=0.314$, $p=0.577)$.

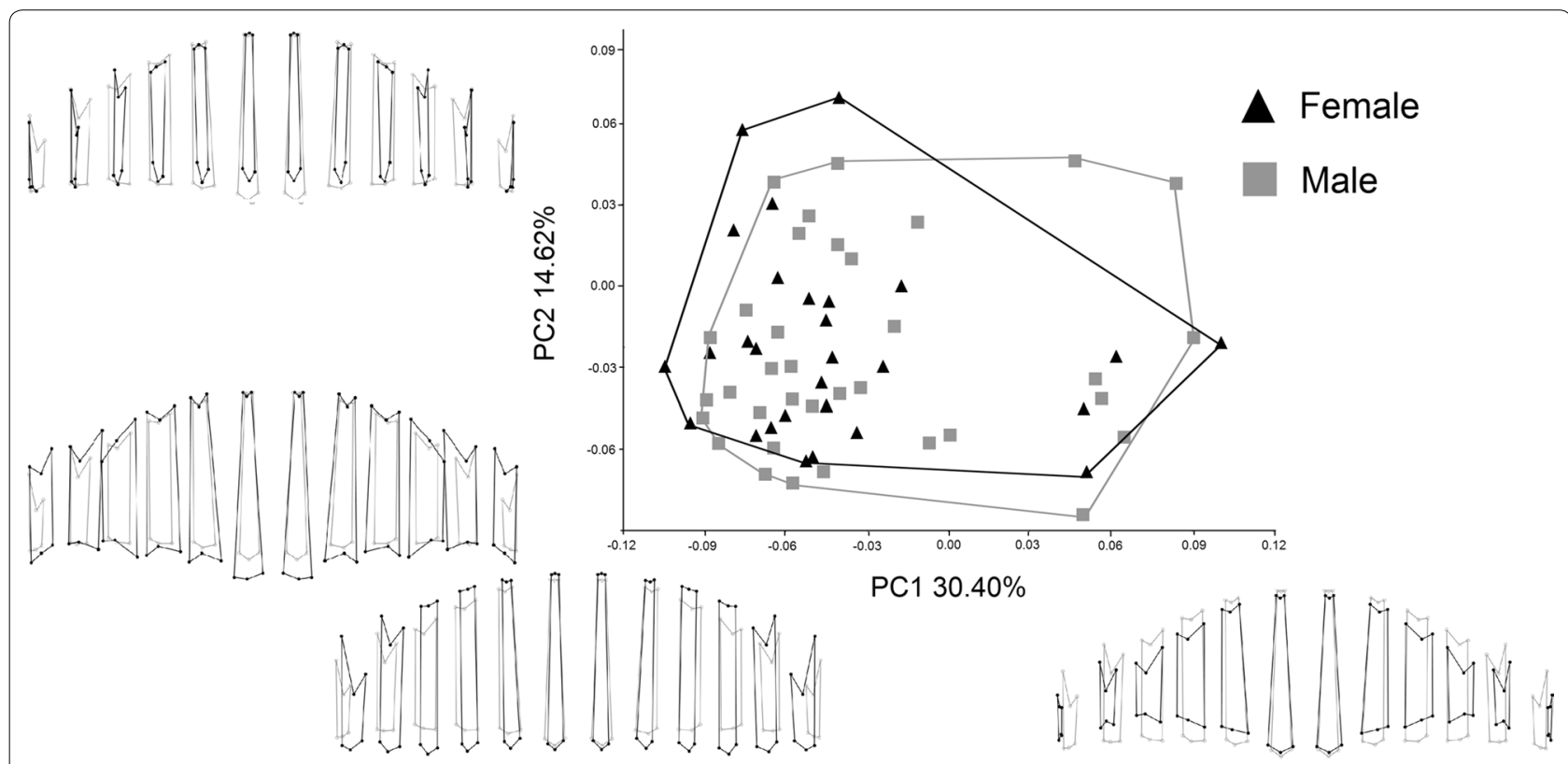

Fig. 2 PCA of tail shapes of the Great Grey Shrike (Lanius excubitor), Museum of Natural History, Leiden, the Netherlands. Grey lines represent the wireframe for the starting shape, and black lines the wireframe for the target shape 


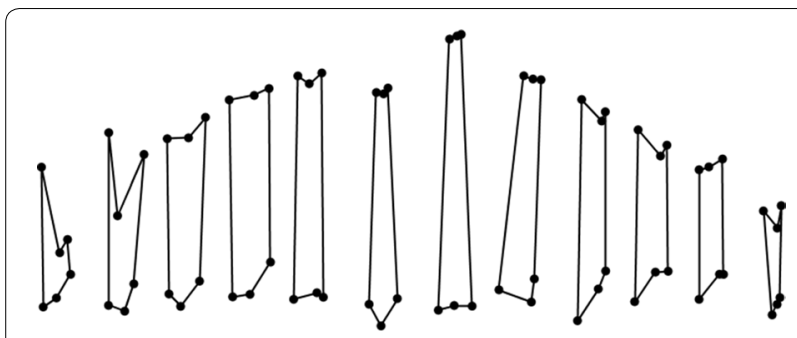

Fig. 3 Directional asymmetry of tail shape of male Great Grey Shrike $(n=35, F=1.46, p=0.0078)$

Table 1 Procrustes ANOVA for the shape of the black area in tails of Great Grey Shrikes (Lanius excubitor), Museum of Natural History, Leiden, the Netherlands

\begin{tabular}{lllrll}
\hline Effect & Sums of squares & Mean square & df & $\boldsymbol{F}$ & $\boldsymbol{p}$ \\
\hline Females & & & & & \\
Individual $^{\mathrm{a}}$ & 0.1945 & 0.0001 & 1890 & 10.95 & $0.0001^{*}$ \\
Side $^{\mathrm{b}}$ & 0.0008 & 0.0000 & 70 & 1.23 & 0.0997 \\
${\text { Ind } \times \text { side }^{c}}$ & 0.0178 & 0.0000 & 1890 & 4.71 & $0.0001^{*}$ \\
Error $^{\mathrm{d}}$ & 0.0078 & 0.0000 & 3920 & & \\
Males & & & & & \\
Individual $^{\mathrm{a}}$ & 0.2670 & 0.0001 & 2380 & 6.36 & $0.0001^{*}$ \\
Side $^{b}$ & 0.0018 & 0.0000 & 70 & 1.46 & $0.0078^{*}$ \\
${\text { Ind } \times \text { side }^{c}}^{0.0420}$ & 0.0000 & 2380 & 6.74 & $0.0001^{*}$ \\
Error $^{\mathrm{d}}$ & 0.0128 & 0.0000 & 4900 & & \\
\hline
\end{tabular}

*Significant differences, $p<0.05$

a The variation between individuals

b Directional asymmetry

c Fluctuating asymmetry

d The residual variation due to measurement error

Spearman correlation showed no significant association between FA score and tail features (growth and fault bars) in either sex of the Great Grey Shrike. However, in females, we observed a negative significant correlation between the number of fault and growth bars (Table 2).

Table 2 Spearman correlation for FA score and male and female tail features of Great Grey Shrikes (Lanius excubitor), Museum of Natural History, Leiden, the Netherlands

\begin{tabular}{lrr}
\hline Tail features & FA score & Fault bars \\
\hline Females & & \\
Fault bars & 0.049 & \\
Growth bars & -0.085 & $-0.376^{*}$ \\
Males & & \\
Fault bars & -0.029 & -0.180 \\
Growth bars & 0.184 & \\
\hline
\end{tabular}

*Significant Spearman coefficient, $p<0.05$
The shape of the black area in the tail displayed no statistically significant association with the tail features in both sexes although in females and males, growth bars were more strongly correlated with tail shape than the number of fault bars. All PLS coefficients were positive, ranging from 0.0514 to 0.0867 (Table 3 ).

\section{Discussion}

The arts and the sciences are two fields which can mix but are normally kept separate, especially when it comes to scientific publications and experiments that require rigorous protocols with no tolerance for flights of imagination. The combination of art and science in this paper is an example of how an artist can highlight a phenomenon that the scientist can then research in depth.

The study of markings in natural (e.g., Yosef et al. 2012) and sexual selection in True Shrikes has been addressed in the past (e.g., Yosef and Pinshow 1989; Tryjanowski and Hromada 2005; Panov 2011) but not from the perspective of what a female could possibly read in the tail markings and asymmetry in Great Grey Shrikes (but see Panov 2011). Instinctively one assumes that symmetry would be the optimal choice but in humans while deviations from symmetry are critical perceptual units in detecting appearance of health the natural subtle asymmetry of the human face may be relatively unimportant for judgment of facial attractiveness (Zaidel et al. 2005). Similarly, Møller (1991) found that in Barn Swallows (Hirundo rustica) males that acquired a mate were more symmetrical in wing and outer tail length than unmated males and females with more asymmetrical tails laid eggs significantly later. He further found that males that survived were less asymmetric than non-survivors. However, one must take into account that because our study was conducted on museum skins, the idea needs to be tested in the field in a wild population and evaluated in relation to other parameters such as breeding success.

The fact that shape and size of the rectrices between the sexes conform to the field data and observations that the sexes in the Great Grey Shrike are very similar (cf. Panov 2011). However, our data have shown that the

Table 3 PLS analyses between the shape of the black area in the tail and two tail and ptilochronological features of female and male Great Grey Shrikes (Lanius excubitor), Museum of Natural History, Leiden, the Netherlands

\begin{tabular}{llllll}
\hline $\begin{array}{l}\text { Shape of the } \\
\text { black area }\end{array}$ & Tail features & & $\boldsymbol{n}$ & RV & $\boldsymbol{p}$ \\
\cline { 2 - 5 } & Fault bars (mm) & Growth bars & & & \\
\hline Females & $0.39 \pm 1.08$ & $39.48 \pm 5.75$ & 28 & 0.0867 & 0.8475 \\
Males & $0.37 \pm 1.15$ & $36.98 \pm 4.73$ & 35 & 0.0514 & 0.0799
\end{tabular}

$n$ denotes the number of individuals, RV the coefficient of the PLS analyses, and $p$ the value of the permutation test 
feathers of males were characterised by more elongated and slender black areas on the feathers than that of the females. It now needs to be seen if this characteristic is evident in the field and can be used to sex the individuals in the field aiding in behavioural studies where not all individuals are always marked successfully (e.g., Keynan and Yosef 2010a, b).

The above is further substantiated by the fact that our results also showed that directional asymmetry (DA) was observed only in males, but fluctuating asymmetry (FA) was noted in both sexes (Table 1). Although chromatic manipulative studies (cf. Yosef et al. 2012) are required to verify if indeed this DA may influence sexual selection in the shrikes, it has been shown to occur in other avian species (Møller 1991, 1994). However, it must be noted that in Lesser Grey Shrike Krištín et al. (2006) concluded that in spite of the fact that the black spot on T5 helped to discriminate between the sexes and was an indicator for male age, it did not reflect the quality or condition of an individual.

Grubb et al. (1991) found that in Northern Cardinals, age and sex influenced the daily growth, the total length and mass of both an induced feather and the original feather. However, owing to our inability to establish the age of the individuals based on the museum data, we were unable to evaluate if asymmetry in the tails was affected in either of the sexes.

Prentice et al. (2008) found no relationship between the occurrence of fault bars and degree of bilateral asymmetry, but concluded that FA and fault bar occurrence should not be used interchangeably as bio-indicators. Similarly, in our study ptilochronology did not statistically correlate with FA. We think that because ptilochronology shows the nutritional condition of an individual while FA shows development instability, which means that this factor is much wider than ptilochronology, and could explain why FA was not associated with growth bars.

This is of great importance because similar studies in the relatively new field of ptilochronology (Grubb 1989) are lacking and are required to establish if indeed growth bars also affect patterning of feather coloration. Lens and Eggermont (2008) concluded that given the intrinsic difficulties associated with FA analysis, ecologists need to combine information from FA with that of other individual-based biomarkers, such as growth-bar dimensions. This has been the assumption on which our study is based and that growth bars reflect symmetry in rectrices, but needs to be further studied on free-ranging individuals.

Also, because we found no significant differences between intra- and inter-observer data, we are confident that the rigorous application of the scientific and artistic techniques by the relevant individuals was of great discipline and precision. This allows us to conclude that in spite of the fact that we have found a special marking in the male rectrix and a greater degree of symmetry, and because our study was conducted on museum skins, we remain unsure as to the importance of these findings for fitness of the Great Grey Shrikes.

\section{Conclusions}

We conclude that the characteristics discovered in this study need to also be verified in the field and if they can be used to sex individuals. Also, chromatic manipulative studies are required to verify if DA influences sexual selection in the Great Grey Shrike and in other avian species, especially the Laniidae spp., with similar tail markings.

\section{Additional file}

Additional file 1: Figure S1. Photo of black contours drawn on standardized template of Great Grey Shrike rectrices in order to control for feather size.

\section{Authors' contributions}

$\mathrm{RY}$ and MB formulated the ideas and conducted the experiment; AMK and PT did the statistical analyses; all authors contributed equally to the writing of the paper. All authors read and approved the final manuscript.

\section{Author details}

${ }^{1}$ Ben-Gurion University of the Negev - Eilat Campus, P.O. Box 272, 88106 Eilat, Israel. ${ }^{2}$ Institute of Zoology, Poznan University of Life Sciences, Wojska Polskiego 71 C, 60-625 Poznań, Poland. ${ }^{3}$ Noordwolde, The Netherlands.

\section{Acknowledgements}

We thank Steven van der Mije, head of vertebrate and invertebrate collections and Pepijn Kamminga, Senior Collection Manager Birds and Mammals, for their hospitality and access to the collection of the Natural History Museum in Leiden.

Competing interests

The authors declare that they have no competing interests.

\section{Availability of data and materials}

Dataset and each of the drawings of the tail feathers will be deposited for future reference at https://www.researchgate.net/profile/Reuven_Yosef.

\section{Consent for publication}

Not applicable.

\section{Ethics approval and consent to participate}

All authors have consented with their participation. Permit of the Naturalis Museum was received prior to our being allowed to work with the skin collection.

\section{Funding}

The study was partially sponsored by a grant of the Polish Ministry of Sciences and Higher Education (Number NN 304375238).

Received: 17 November 2017 Accepted: 27 December 2017

Published online: 08 January 2018 


\section{References}

Andersson M. Sexual selection. Princeton: Princeton University Press; 1994

Balmford A, Jones IL, Thomas ALR. On avian asymmetry: evidence of natural selection for symmetrical tails and wings in birds. Proc R Soc B. 1993;252:245-51.

Blackenhorn W, Reusch T, Mulhauser C. Fluctuating asymmetry, body size and sexual selection in the dung fly Sepsis cynipsea: testing the good genes assumptions and predictions. J Evol Biol. 1998;11:735-53.

Bujoczek M, Ciach M, Yosef R. Road-kills affect avian population quality. Biol Conserv. 2011;144:1036-9.

Darwin C. The descent of man, and selection in relation to sex. London: Murray; 1871.

Degen AA, Pinshow B, Yosef R, Kam M, Nagy KA. Energetics in Northern Shrikes: nestling growth rate and field metabolic rates of adults. Ecology. 1992;73:2273-83.

Dylewski L, Tryjanowski P, Mikula P, Morelli F, Yosef R. Social media and scientific research are complementary-YouTube and shrikes as a case study. Sci Nat. 2017;104:48. https://doi.org/10.1007/s00114-017-1470-8.

Endler JA. Evolutionary implications of the interactions between animal signals and the environment. In: Espmark Y, Amundsen T, Rosenqvist G, editors. Animal signals: signalling and signal design in animal communication. Trondheim: Tapir Academic Press; 2000. p. 11-46.

Gombobaatar S, Yosef R, Odkhuu B. Brandt's Vole density affects reproduction of Upland Buzzards. Ornis Fennica. 2009;86:1-9.

Gonzalez-Jaramillo M, De Le Cueva H. Natural tail streamer asymmetry in male Magnificent Frigatebirds Fregata magnificens: influence on mate selection and male parental care performance. Mar Ornithol. 2010;38:85-90.

Grubb TC Jr. Ptilochronology: feather growth bars as indicators of nutritional status. Auk. 1989;106:314-20.

Grubb TC Jr. Ptilochronology: a review and prospectus. Curr Ornithol. 1995;12:89-114.

Grubb TC Jr. Ptilochronology. Oxford: Oxford University Press; 2006.

Grubb TC Jr, Yosef R. Habitat-specific nutritional condition in Loggerhead Shrikes (Lanius /udovicianus): evidence from ptilochronology. Auk. 1994;111:756-9.

Grubb TC Jr, Waite TA, Wiseman AJ. Ptilochronology: induced feather growth in Northern Cardinals varies with age, sex, ambient temperature, and day length. Wilson Bull. 1991;103:435-45.

Hamilton WD, Zuk M. Heritable fitness and bright birds: a role for parasites? Science. 1982;218:384-7.

Hernandez MA, Campos F, Gutierrez-Corchero F, Amezcua A. Identification of Lanius species and subspecies using tandem repeats in the mitochondrial DNA control region. Ibis. 2004;146:227-30.

Hromada M, Kuczyński L, Krištín A, Tryjanowski P. Animals of different phenotype differentially utilise foraging niche-the Great Grey Shrike case study. Ornis Fennica. 2003a;80:71-8.

Hromada M, Kuczyński L, Skoracki M, Antczak M, Tryjanowski P. The importance of the bird collections and metadata in regional museums: a case of great grey shrike Lanius excubitor specimens from Sarisske Museum, Bardejov, Slovakia. Bull Br Ornithol Club Suppl. 2003b;123A:226-33.

Keynan O, Yosef R. Temporal and sexual differences of impaling behavior in Southern Grey Shrike (Lanius meridionalis). Behav Proc. 2010a;85:47-51.

Keynan O, Yosef R. Precipitation affects reproduction of Southern Grey Shrike (Lanius meridionalis). Wilson J Ornithol. 2010b;122:334-9.

Klingenberg CP. MorphoJ: an integrated software package for geometric morphometrics. Mol Ecol Resour. 2011:11:353-7.

Klingenberg CP. Analysing fluctuating asymmetry with geometric morphometrics: concepts, methods, and applications. Symmetry. 2015;7:843-934

Krištín A, Valera F, Hoi C, Hoi H. Do melanin-based tail patterns predict individual quality and sex in Lesser Grey Shrikes Lanius minor? J Ornithol. 2006;148:1-8

Lens $\mathrm{L}$, Eggermont $\mathrm{H}$. Fluctuatinig asymmetry as a putative marker of humaninduced stress in avian conservation. Bird Conserv Int. 2008;18:S125-43.

Lorenz K, von St Paul U. Die entwicklung des Spiessens und Klemmens bei den drei Wurgerarten Lanius collurio, L. senator und L. excubitor. J Ornithol. 1968;109:137-56 (in German).

Markow TA, Clarke GM. Meta-analysis of the heritability of developmenta stability: a giant step backward. J Evol Biol. 1997;10:31-7.

Mayburg WJ, Rayner JMV, Couldrick LB. Lift generation by the avian tail. Proc $\mathrm{R}$ Soc Lond B. 2001;268:1443-8.
Mclntosh AR, Bookstein FL, Haxby JV, Grady CL. Spatial pattern analysis of functional brain images using partial least squares. Neuroimage. 1996:3:143-57.

Mitteroecker P, Gunz P. Advances in geometric morphometrics. Evol Biol. 2009:36:235-47.

Møller AP. Sexual ornament size and the cost of fluctuating asymmetry. Proc R Soc B. 1991;243:59-62.

Møller AP. Sexual selection in the Barn Swallow (Hirundo rustica). IV. Patterns of fluctuating asymmetry and selection against asymmetry. Evolution. 1994;48:658-70.

Møller AP, Höglund J. Patterns of fluctuating asymmetry in avian feather ornaments: implications for models of sexual selection. Proc R Soc Lond B. 1991;245:1-5.

Møller AP, Thornhill R. A meta-analysis of the heritability of developmental stability. J Evol Biol. 1997;10:1-16.

Møller AP, Barbosa A, Cuervo JJ, de Lope F, Merino S, Saino N. Sexual selection and tail streamers in the Barn Swallow. Proc R Soc Lond B. 1998:265:409-14.

Morris MR, Casey K. Female swordtail fish prefer symmetrical sexual signal. Anim Behav. 1998:55:33-9.

Olsson U, Alström P, Svensson L, Aliabadian M, Sundberg P. The Lanius excubitor (Aves, Passeriformes) conundrum - taxonomic dilemma when molecular and non-molecular data tell different stories. Mol Phylog Evol. 2010;55:347-57.

Ortolani A. Spots, stripes, tail tips and dark eyes: predicting the function of carnivore colour patterns using the comparative method. Biol J Linn Soc. 1999;67:433-76.

Outomuro D, Johansson F. A potential pitfall in studies of biological shape: does size matter? J Anim Ecol. 2017:86:1447-57.

Palmer AR. Detecting publication bias in meta-analyses: a case study of fluctuating asymmetry and sexual selection. Am Nat. 1999;154:220-33.

Palmer AR. Quasireplication and the contract of error: lessons from sex ratios, heritabilities and fluctuating asymmetry. Annu Rev Ecol Syst. 2000;31:441-80.

Panov EN. The True Shrikes (Laniidae) of the world-Ecology, behavior and evolution. Sofia: Pensoft Publishers; 2011. p. 910.

Pennycuick CJ. Mechanics of flight. In: Farner DS, King JR, Parkes KC, editors. Avian biology, vol. V. New York: Academic Press; 1975. p. 1-73.

Prentice S, Jobes AP, Burness G. Fault bars and fluctuating asymmetry in birds: are the two measures correlated? J Field Ornithol. 2008;79:58-63.

Rohlf F. BIOMstat ver. 4.0, tpsDig2. Exeter Software, Stony Brook, New York, USA. 2010

Shykoff JA, Møller AP. Fitness and asymmetry under different environmental conditions in the barn swallow. Oikos. 1999:86:152-8.

Slice DE. Geometric morphometrics. Annu Rev Anthropol. 2007;36:261-81.

Sneddon LU, Swaddle JP. Asymmetry and fighting performance in the shore crab, Carcinus maenas. Anim Behav. 1999;58:431-5.

Swaddle JP. On the heritability of developmental stability. J Evol Biol. 1997;10:57-61

Swaddle JP. Fluctuating asymmetry, animal behaviour, and evolution. Adv Study Behav. 2003:32:169-205.

Swaddle JP, Cuthill IC. Preference for symmetric males by female zebra finches. Nature. 1994:367:165-6.

Szczykutowicz A, Adamski Z, Hromada M, Tryjanowski P. Patterns in the distribution of avian lice (Phthiraptera: Amblycera, Ischnocera) living on the great grey shrike Lanius excubitor. Parasitol Res. 2006;98:507-10.

Thomas ALR. The aerodynamic costs of asymmetry in the wings and tail of birds: asymmetric birds can't fly around corners. Proc R Soc Lond B. 1993;254:181-9.

Tryjanowski P, Hromada M. Do males of the great grey shrike, Lanius excubitor, trade food for extrapair copulations? Anim Behav. 2005;69:529-33.

Vøllestad LA, Hindar K, Møller AP. A meta-analysis of fluctuating asymmetry in relation to heterozygosity. Heredity. 1999;83:206-18.

Votypka J, Simek J, Tryjanowski P. Blood parasites, reproduction and sexual selection in the Red-backed Shrike (Lanius collurio). Ann Zool Fenn. 2003:40:431-9.

Yosef R, Grubb TC Jr. Resource dependence and territory size in Loggerhead Shrikes (Lanius ludovicianus). Auk. 1994;111:465-9.

Yosef R, Pinshow B. Cache size influences reproductive success in the Northern Shrike, Lanius excubitor. Auk. 1989;106:418-21. 
Yosef R, Pinshow B. Impaling in shrikes: a behavioral and ontogenic perspective. Behav Proc. 2005;69:363-7.

Yosef R, Zduniak P, Tryjanowski P. Unmasking Zorro: functional importance of the facial mask. Behav Ecol. 2012;23:615-8.
Zaidel DW, Aarde SM, Baig K. Appearance of symmetry, beauty, and health in human faces. Brain Cogn. 2005;57:261-3.

Zeldith ML, Swiderski DL, Sheets HD, Fink WL. Geometric morphometrics for biologists: a primer. New York: Academic Press; 2004.

Submit your next manuscript to BioMed Central and we will help you at every step:

- We accept pre-submission inquiries

- Our selector tool helps you to find the most relevant journal

- We provide round the clock customer support

- Convenient online submission

- Thorough peer review

- Inclusion in PubMed and all major indexing services

- Maximum visibility for your research

Submit your manuscript at

www.biomedcentral.com/submit 